\title{
FAUSST: bridging the gap between steel and fibre- reinforced materials
}

\author{
Rafael Luterbacher ${ }^{1}$, Lars Molter ${ }^{2}$, André Sumpf ${ }^{3}$, , Rigo Peters ${ }^{4}$ \\ 1) Center of Maritime Technologies e.V., luterbacher@cmt-net.org, Bramfelder Str. 164, 22305 \\ Hamburg, Germany \\ 2) Center of Maritime Technologies e.V., molter@cmt-net.org, Bramfelder Str. 164, 22305 Hamburg, \\ Germany
}

3) Schweißtechnische Lehr- und Versuchsanstalt Mecklenburg-Vorpommern $\mathrm{GmbH}$, sumpf@slv-rostock.de, Alter Hafen Süd 4, 18069 Rostock, Germany

4) Schweißtechnische Lehr- und Versuchsanstalt Mecklenburg-Vorpommern GmbH, peters@slv-rostock.de, Alter Hafen Süd 4, 18069 Rostock, Germany

\section{Keywords}

Composite, Hybrid Material, Steel, Textile, Transition Joint, Multi-material Joining

\begin{abstract}
Multi-material design is commonly used within lightweight applications to meet certain design constraints. One common challenge across the different industry fields is the joining of materials of different material classes. Bonding and mechanical joining are generally used to overcome this issue. However, in some application fields, such as in the shipbuilding industry, where the interest of applying fibre-reinforced materials is increasing, these processes are not currently feasible due to regulatory and current technical constraints. One potential solution is FAUSST, a textile based transition joint. FAUSST is a hybrid knitted fabric, which is composed of $100 \%$ steel on one side and on the other of $100 \%$ glass fibres. The steel side is welded to a flat steel and the transition element is subsequently integrated via lamination processes within a fibre-reinforced component. Afterwards, this component is e.g. joined to a steel structure by welding. Depending on the design of the transition element, loads of up to $120 \mathrm{kN}$ per meter joint can be transferred in the presented design with an overlap length of only $10 \mathrm{~mm}$. This transition element, therefore, may lead to more lightweight designs with smoother surfaces for aesthetical, aerodynamic or hydrodynamic surfaces.
\end{abstract}

\section{Introduction}

The boat and yacht industries have been pioneering in the application of fibre-reinforced polymers (FRP) by developing different techniques for wet lay-up production, e.g. SCRIMPTM [1]. Full FRP or hybrid FRP-metal boats and yachts are commonly manufactured. Partly, the technologies in this sector have been adapted and further developed in the aeronautic, automotive and construction sector. In contrast, the shipbuilding industry has been much more reluctant to the implementation of FRP or other novel materials. This is mainly due to the regulatory framework - e.g. SOLAS design code [2] -, which implies that mainly steel is used as a structural material, as the risk of fire is one of the main design considerations. In the last decades, the regulatory framework has been changed allowing the usage of materials such as aluminium or FRP, depending on operational or risk mitigating design considerations $[2,3]$. Therefore, currently the question is rather "when" than "if" FRP will be implemented within the production of cruise or other commercial ships. First examples of successful FRP implementation already exist, such as the exchange of steel with FRP profiles for the decks in a car carrier leading to weight reductions of up to $25 \%$ for this structure [4]. However, for stability reasons, the ships need a minimum draught, meaning that a multi-material design and manufacturing process will always be preferred. 
This opens a variety of challenges for the shipbuilding industry, such as how FRP will be introduced within the design and manufacturing processes, but also how the FRP will be joined to the steel structure. Within the project FAUSST, a novel joining solution between steel and FRP structures is developed with focus on an application within the ship building industry.

\section{State of the art}

Within multi-material design, one of the key challenges is the joining process of materials belonging to two different material classes, as their differences in stiffness and thermal expansion coefficient must be considered. Commonly used processes are bonding [5] and mechanical joining [6]. The former has the drawback that it is a very sensitive process. This is a critical limiting factor, as the shipbuilding industry has working conditions comparable to those on a building site, i.e. exposure to changing temperature and humidity. For the latter, the minimal steel thickness of $5 \mathrm{~mm}$, the tight tolerances needed and localised load transfer also render it a non-optimal joining process for shipbuilding working conditions. Within the body of literature a variety of other processes such as overlamination [7] or transition joints [8] can be found. However, the focus is on Carbon FRP for aeronautical applications, where cost constraints are lower than for the shipbuilding industry.

\section{Materials and methods}

\subsection{FAUSST Concept}

FAUSST stands for "Faser und Stahl Standard Verbinder" (in German for Fibre and steel standardised joint) and is a transition element between fibre-reinforced materials and steel. Figure 1 summarises the process chain of manufacturing the semi-finished product FAUSST, as well as the implementation within a FRP and steel structure.

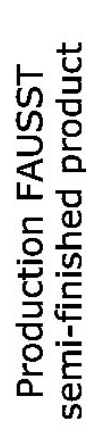

1.) Knitting hybrid fabric
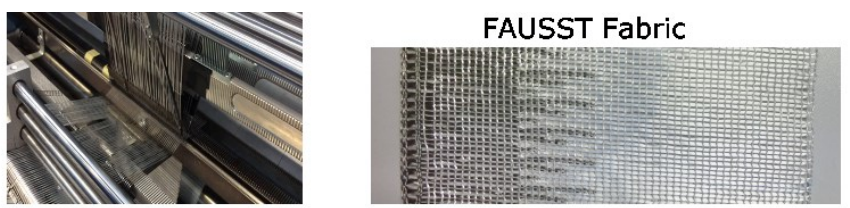

2.) Machining of flat steel

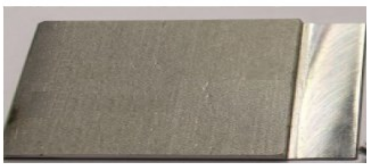

3.) Joining of hybrid fabric and flat steel
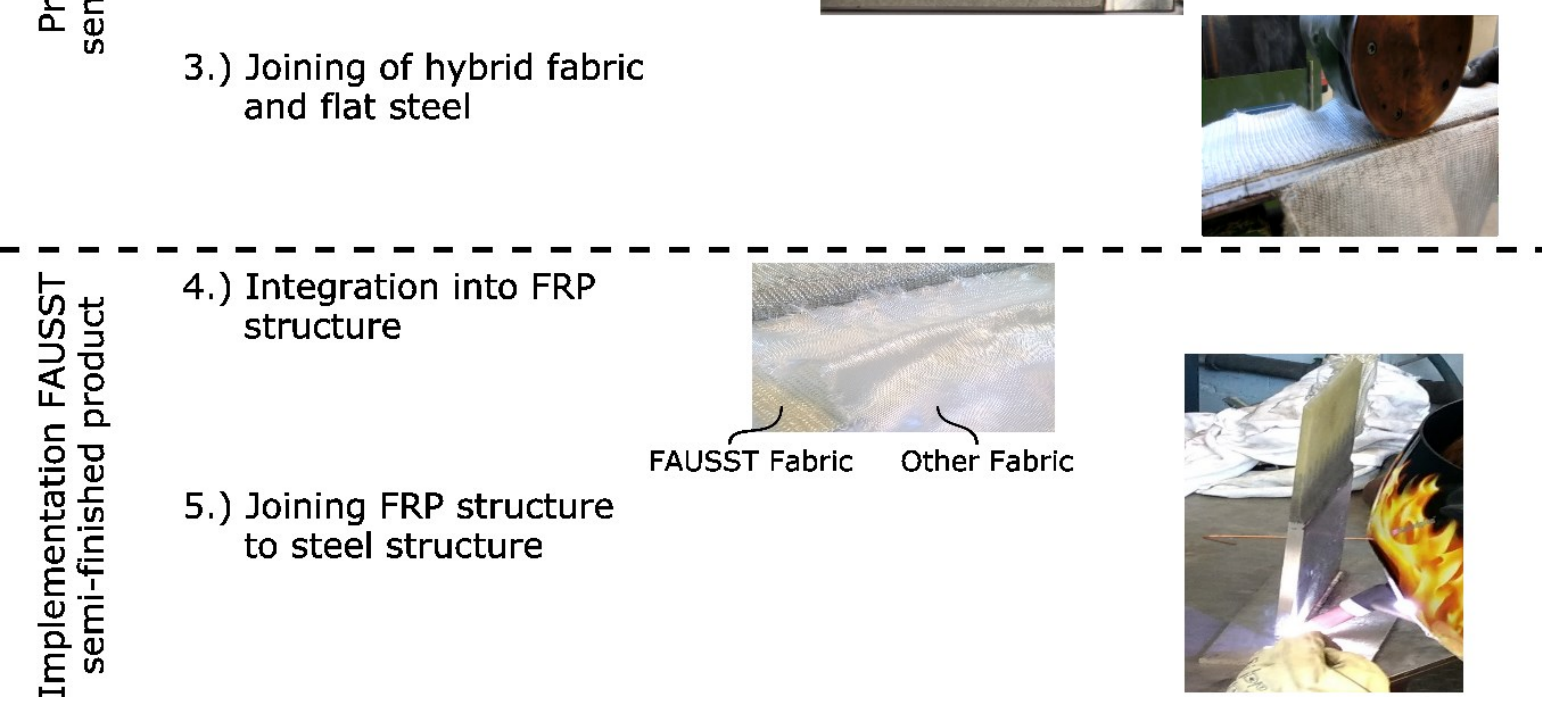

Figure 1: Process chain FAUSST 
Two different phases are distinguished: (1) the production of the semi-finished product FAUSST and (2) the implementation of it to join a FRP and a steel structure.

\subsubsection{Production of the FAUSST semi-finished product}

The FAUSST semi-finished product is composed of a hybrid fabric, which is welded to a flat steel. The warp knitted weft inserted hybrid fabric is designed in cooperation with Fritz Moll Textilwerke $\mathrm{GmbH}$ \& Co KG (Germany) and manufactured using a Decortronic 1000/EL electronic crochet knitting machine (Comez International s.r.l., Italy). The fabric is composed of 3 layers of weft in-lays, 2 layers of warp inlays, which are connected via open lap pillar stitches [9]. The pattern of the ca. $150 \mathrm{~mm}$ wide fabric is designed in a way that ca. $10 \mathrm{~mm}$ and ca. $90 \mathrm{~mm}$ of the fabric are composed of $100 \%$ steel and $100 \%$ glass fibres, respectively. The transition part has a changing length of the weft in-lay of the two yarn systems, both in direction of length and thickness, to reduce the stiffness mismatch between the steel and glass fibres and to assure an interlocking of the fibre systems (see Figure 1). For the steel fibres Bekinox VN8.1.1.40Z from Bekaert and for the glass fibres EC-16-200-350-U from PD-Glasseiden were used.

The function of the flat steel is to transfer the loads between the steel and the FRP structure. In order to prevent secondary loadings, such as out of plane bending of the FRP, which could lead to premature failure, the flat steel may be machined in order to reduce the load eccentricity. The flat steel has to be of a certain length to (1) allow for final machining for adaptation to the steel structure and (2) prevent heating up of the FRP component due to heat transfer during welding to the steel structure.

In a last step, one or several layers of FAUSST fabric are first spot welded to the (machined) flat steel and then resistance seam welded (UN63, LEW) to create a permanent connection between the fabric and flat steel. Currently, this process is performed manually, however, it can be easily automated.

\subsubsection{Implementation of the FAUSST semi-finished product}

During the lamination process of a FRP component, the FAUSST connector is integrated into the component by overlaminating the individual FAUSST layers with the component plies (see Figure 1 similar to the process of ply splicing). It has to be noted, that the process has been developed for liquid resin processes such as RTM or VARTM [1]. However, using resin films, similar results should be obtained for prepreg materials using a SQRTM process [10]. The load transfer between the FAUSST layers and the component plies therefore relies mainly on the mechanical properties of the resin and the overlap length [11]. In case that higher loads are to be transferred, thickness reinforcement like tufting [12] would be feasible. However, in that way the manufacturing complexity is increased.

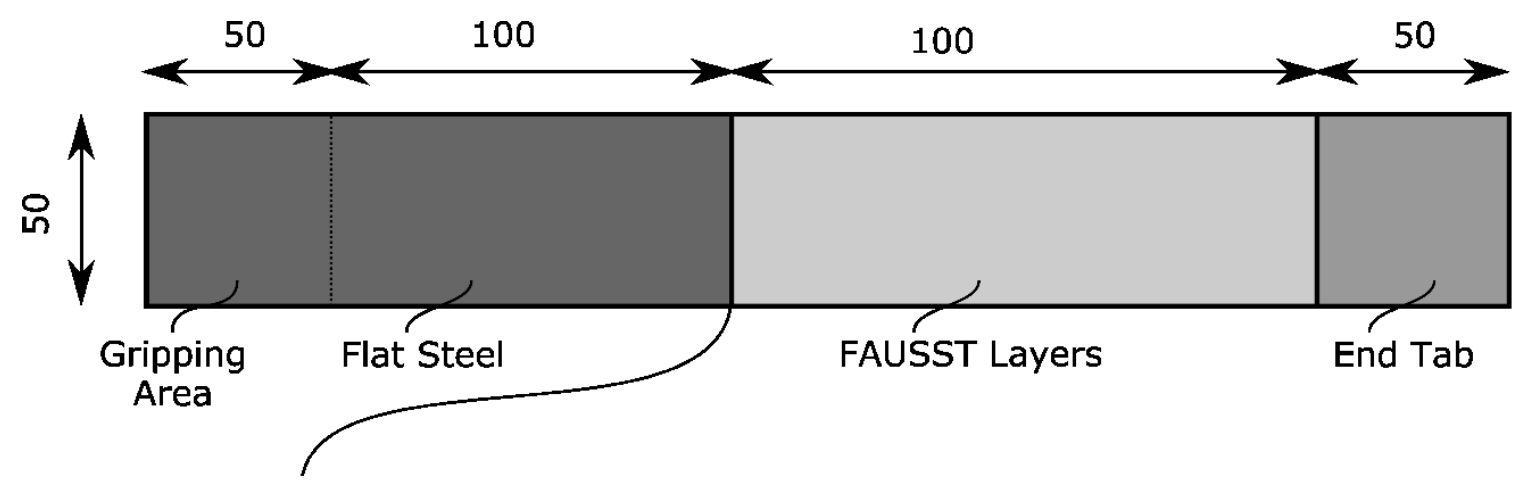

\section{Edge view at weld seam:}

ID A

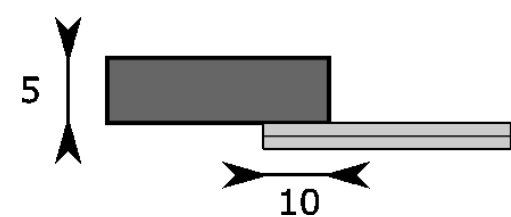

ID B

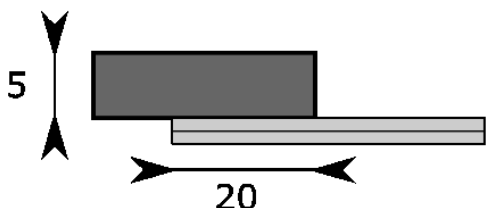

ID C

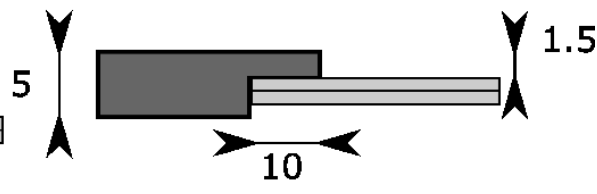

Figure 2: Specimen geometry and welding details. Note: specimens not depicted to scale 
In a last step, the cured FRP component is welded to a steel structure at the steel section integrated via FAUSST.

\subsection{Experimental Methods}

\subsubsection{Materials}

A total of three different configurations with two layers of FAUSST fabric were manufactured. Figure 2 shows the specimen geometry. For ID A and B the flat steel was not machined and the FAUSST fabrics were directly welded to it with an overlap length of $10 \mathrm{~mm}$ and $20 \mathrm{~mm}$, respectively. For ID C, the flat steel was machined in order to align the centre lines of the steel and the FRP parts.

The used FAUSST fabric was knitted as described in 3.1.1 with a gauge of 10 needles per inch and a stitch density of 2.75 stitches per $\mathrm{cm}$.

As we wanted to determine the joint strength only, no additional fibre material was used. Using a standard VARTM process [1], the panels were infused with Ampreg 22 with standard hardener (Gurit) and then cured according to the manufacturer recommendation at $80{ }^{\circ} \mathrm{C}$ for $5 \mathrm{~h}$.

\subsubsection{Test protocol}

From the manufactured panels, end tabs were connected via secondary bonds on the FRP side. Then, $50 \mathrm{~mm}$ wide specimens were cut using a saw. At last three specimens were tested for each configuration. Tensile tests were performed on a universal testing machine (Zwick Z600) in accordance with ASTM D3039 under displacement control.

\section{Results}

Figure 3 shows representative load displacement curves for the tested configurations and Table 1 summarises the test results.

All configurations behaved linearly to failure and had a similar apparent stiffness. Prior to failure, at around $75 \%$ of the failure load, first damages in terms of loss of linearity were visible. The lowest strength was obtained for ID A with $4.7 \mathrm{kN}$, whereas ID B and ID C had a $15 \%$ and $30 \%$ higher failure load. As the specimens do not have a constant cross section, the failure load is normalised by the specimen width. Every specimen failed at the transition from the $100 \%$ steel part to the hybrid fabric, where the load is only transferred through the steel fibres.

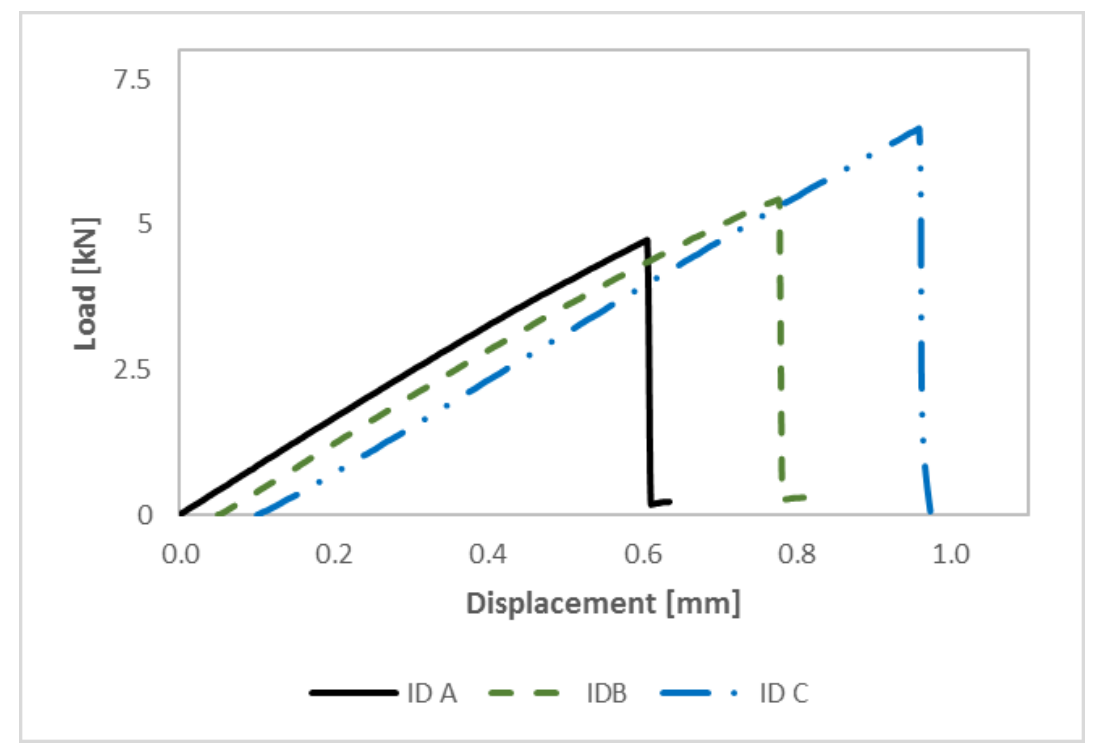

Figure 3: Representative Load-Displacement curves. Note: Curves are staggered for better visualisation. 
Table 1: Test results. Average values from at least three specimens. One standard deviation in brackets.

\begin{tabular}{llll}
\hline & $\begin{array}{l}\text { First damage } \\
{[\mathbf{k N}]}\end{array}$ & $\begin{array}{l}\text { Failure Load } \\
{[\mathbf{k N}]}\end{array}$ & $\begin{array}{l}\text { Joint Strength } \\
{[\mathbf{k N} / \mathbf{m}]}\end{array}$ \\
\hline ID A & $3.7(0.3)$ & $4.7(0.1)$ & $94.8(1.6)$ \\
ID B & $3.9(0.1)$ & $5.4(0.2)$ & $108.0(3.1)$ \\
ID C & $5.1(0.6)$ & $6.1(0.8)$ & $121.5(16.4)$ \\
\hline
\end{tabular}

\section{Discussion and conclusion}

\subsection{Discussion}

As expected, the highest failure load was observed for the ID C, where the flat steel was machined to minimise out of plane deformation due to the load eccentricity. This is feasible when the final ply thickness of the FAUSST layers and additional fibrous material is known. However, individualising the flat steel for every application case is not feasible due to economic reasons. The attempt to have a simplified flat steel design led to $12 \%$ and $23 \%$ lower failure loads for ID B and A, respectively. These designs have the benefit that the process chain (Figure 1 ) is reduced by one step, thereby reducing the manufacturing cost and time of the semi-finished product FAUSST. One other potential approach currently under research, to minimise the eccentricity is the design of symmetric flat steel geometries. Alternatively, within the joint design two FAUSST half-finished products could be used to obtain a symmetric joint.

The results obtained can be compared with an adhesive joint by normalising the failure load with the overlap area. This results in an average lap shear strength of $9.4 \mathrm{MPa}, 5.4 \mathrm{MPa}$ and $12.2 \mathrm{MPa}$ for ID A, $\mathrm{B}$ and C, respectively, showing that FAUSST is competitive compared to bonded joints. Generally, lap shear strengths of adhesives for multi-material design range between $5 \mathrm{MPa}$ and $15 \mathrm{MPa}$, depending on the type of materials, adhesive behaviour and surface preparation.

As every specimen failed at the same location, this weak spot can potentially be eliminated in further designs of the knitted fabric. At the failure location, only the in-lay steel fibres and the matrix material are present. Therefore, either the amount of steel fibres can be increased by having a higher stitch density, another fibre system with a higher strength or by changing the knitting pattern to improve the fabric design.

\subsection{Conclusion}

The results of a textile-based transition joint show that loads from $95 \mathrm{kN} / \mathrm{m}$ to $122 \mathrm{kN} / \mathrm{m}$ can be successfully transferred from a steel to a FRP structure. Alternatively, this technology can also be used for load introductions in FRP materials, which have a low bearing strength.

The manufacturing processes of the half-finished product FAUSST is based on standard processes found in the textile and welding industry, making the product suitable for industrialisation and mass production. The implementation phase of the FAUSST connector to join a FRP and steel structure is also based on standard processes such as lamination and welding reducing the need for specialised processes and equipment.

Currently, the research focus lies on the shipbuilding industry and on the connection between Glass FRP and steel. However, it is feasible to combine other materials within the knitted fabric, such as aluminium, glass and carbon fibres. Furthermore, thinner flat steels can be used, opening this joining method also to other sectors such as the automotive, rail and construction industry. 


\section{Acknowledgments}

The authors would like to thank the German "Industrielle Gemeinschaftsforschung IGF" for funding this project (18785 BG); the Schweißtechnische Lehr- und Versuchsanstalt Mecklenburg-Vorpommern and Halle for the welding and testing of the specimens; the company Fritz Moll GmbH for the support in designing and developing the FAUSST fabric; the company Comez International S.R.L for the knitting of the fabric; the Meyer Werft for supplying the steel profiles; Fraunhofer IGP from Rostock for the support during specimen fabrication and the other members of the project committee for their valuable input.

\section{References}

[1] Åström, B.T.: Liquid Molding. In: Manufacturing of Polymer Composites. Cheltenham: Nelson Thornes, 2002 (Original work published 1997), pp. 219-234.

[2] Stevens, R.; Quinn, S.; et al.: Modernising composite materials regulations: A position paper. University of Southampton, 2017.

[3] Hoppe, H.: International Regulations for high-speed craft. An overview. In: Proceedings of the International Conference on Fast Sea Transportation, FAST'2005, 2005, pp. 1-7.

[4] JEC: A car carrier 25\% lighter by using sandwich panels. JEC Composites Web, 2017. http://www.jeccomposites.com/knowledge/international-composites-news/car-carrier-25-lighterusing-sandwich-panels. (accessed 13 July 2017).

[5] Sawson, R.: How adhesive bonding has made gluing cars together a reality. Automotive World, 2013. https://www.automotiveworld.com/megatrends-articles/adhesive-bonding-made-gluingcars-together-reality/ (accessed 13 July 2017).

[6] Thoppul, S.; Finegan, J., Gibson, R.F.: Mechanics of mechanically fastened joints in polymer-matrix composite structures - A review. Comp.Sci.Tech., 69 (2009), pp.201-329. doi: 10.1016/j.compscitech.2008.09.037

[7] Boyd, S.; Blake, J.I.R.; Shenoi, R.A.; Kapadia, A.: Integrity of hybrid steel-to-composite joints for marine applications. Proc. of the Inst. of Mech. Eng. Part M: J. of Eng. for the Marit. Env., 218 (2004), pp.235-246. doi: 10.1177/147509020421800403

[8] Woizeschke, P.; Schumacher, J.; et al.: Joining of Aluminum and CFRP Parts using titanium foils as transition elements. In: Proceedings of the Euro Hybrid Materials and Structures, 2014, pp.6975.

[9] Spencer D.J.: Basic Warp Knitting Principles. In: Knitting Technology. Oxford: Pergamon Press, 1983, pp. 258-269.

[10] Black,S.: SQRTM enables net-shape parts. Composites World Web, 2010. http://www.compositesworld.com/articles/sqrtm-enables-net-shape-parts (accessed 13 July 2017).

[11] Ahamed, J.; Joosten,M.; et al.: Ply-interleaving technique for joining hybrid carbon/glass fibre composite materials. Comp. Part A, 84 (2016), pp. 134-146. doi: 10.1016/j.compositesa.2016.01.010

[12] Dell'Anno, G.; Treiber, J.W.G.; Partridge, I.K.: Manufacturing of composite parts reinforced through-thickness by tufting. Robot. Comp. Int. Manuf., 37 (2016), pp. 262-272. doi: 10.1016/j.rcim.2015.04.004 